\title{
Embodied-Self-monitoring
}

\section{Embracing the Context for Adherence to Physical Rehabilitation in the Design for Self- monitoring}

\author{
Naveen L Bagalkot \\ Srishti Labs, Srishti School of Art, Design and \\ Technology, \\ Bangalore, India \\ naveen@srishti.ac.in
}

\author{
Tomas Sokoler \\ Interaction Design Group, \\ IT University of Copenhagen \\ Denmark \\ sokoler@itu.dk
}

\begin{abstract}
Physical rehabilitation is increasingly recommending the rehabilitees to integrate the prescribed therapy with the specific situations of their homes as a way of encouraging adherence. In this paper, we explore how designers can draw from the physical rehabilitation practice to embrace the already ongoing ways in which the rehabilitees adhere to their prescriptions in their homes. To orient the designers towards embracing the rehabilitee engagement with the social and physical settings at home, we present the theoretical concept of embodied-self-monitoring. We demonstrate the fruitfulness of the concept by reporting findings from three design explorations. Through the presentation of the concept and the findings, we open the space for the community to not only consider how the context at home influences adherence, but to embrace this relation between context and adherence to design pervasive selfmonitoring technology that the rehabilitees can engage with and make them an integral part of this emergent context.
\end{abstract}

Physical rehabilitation; self-monitoring; design; embodied-selfmonitoring; context

\section{INTRODUCTION}

The increasing cost of institutional healthcare to society has triggered an ever-growing interest in moving healthcare services beyond the boundaries of hospitals and clinics. Moving parts of healthcare processes into the private homes and everyday life of the patients means an increased responsibility for people to actively engage in managing their health conditions.

Case in point is the field of physical rehabilitation. In general, a physical rehabilitation process involves consultations with professional physiotherapists, who recommend exercise therapies based on the particular diagnosis of the injury. The rehabilitation process also involves periodic sessions at the clinic where the rehabilitees ${ }^{1}$ perform the exercises under the guidance of the physiotherapists. In between these periodic sessions, the rehabilitees are encouraged to adhere to the treatment by performing the prescribed exercises at home on a

Individuals undergoing rehabilitation therapy. daily basis. Performing the exercises at home is considered as a key element of being successfully rehabilitated.

However, there is a lack of adherence amongst the rehabilitees when at home. Research $[7,26]$ has found that it is difficult for the rehabilitees to adhere with their treatment and perform the exercises at home consistently. These studies find that performing rehabilitation exercises at home is influenced by the social, cultural and material circumstances of the individual rehabilitees. Drawing from this understanding, the physiotherapists are increasingly moving away from direct application of therapy towards prescribing rehabilitation therapy procedures and goals that suit the specificities of the individual rehabilitees context at home [21,22,23,24]. In particular, the physiotherapists encourage the rehabilitees to use their activities of daily living (ADL) as means for integrating the therapy exercises with the context of home.

Meanwhile, there is an increasing body of work that design pervasive technology for supporting self-monitoring as a means for encouraging adherence $[8,9,10,17,18,19$,etc.]. In this paper we explore the question of how this body of work can draw from the field of physical rehabilitation to embrace the particular ongoing ways in which the rehabilitees adhere to their prescriptions at their homes. In this exploration we take a phenomenological perspective [11] as a lens to look at the settings where the rehabilitees exercise when at home. This perspective highlights how the rehabilitees engage with a host of things and people (such as, chairs, beds, spouse, friends, etc.) as resources to perform their exercises at home. Through this engagement with the everyday physical and social particularities of their homes, the rehabilitees create a particular context for adhering to the prescribed therapy.

To orient the designers towards embracing the rehabilitee engagement with the social and physical settings at home, we present the theoretical concept of embodied-self-monitoring. By embracing we mean not just acknowledging that the context where the rehabilitees adhere to their therapy is emergent, but to take advantage of this emergence in the design of pervasive self-monitoring technology. Embodied-self-monitoring is our phenomenological take on the well-established concept of selfmonitoring $[16,30]$ to foreground how a particular context for 
adherence emerges. We define embodied-self-monitoring as: Measuring, recording, observing, and performing other such self-monitoring actions through engaging with the particularities of a setting for adhering to prescribed treatment or therapy.

We explore this definition in three particular situations of designing for self-monitoring of physical rehabilitation in India. In this paper we report on the findings synthesized from these explorations in line with the methodology of conceptdriven interaction design research [28]. In particular we discuss how by designing to support embodied-self-monitoring we offer three possible opportunities for the rehabilitees to shape the ways through which they adhere to the prescribed therapy. These are the three opportunities:

1. To integrate the exercises with the objects they live with.

2. To integrate the exercises with other everyday activities.

3. To integrate the exercises with intimate social relations.

Through these findings we demonstrate how the theoretical concept of embodied-self-monitoring gave us the ground to embrace the already ongoing ways through which the rehabilitees engaged with the particularities of their home and adhered with the therapy. Moreover, these findings give concrete pointers to how designers of self-monitoring tools can draw on the knowledge of the physiotherapists who encourage the rehabilitees to integrate exercises with ADL. Through this articulation we invite the pervasive healthcare community to further explore the possibilities embodied-self-monitoring holds for designing pervasive self-monitoring technology that draws on physiotherapy practice of integrating therapy to the specific situations of the individual rehabilitees.

\section{PHYSICAL REHABILITATION PRACTICE: FOCUSING ON SPECIFIC INDIVIDUAL SITUATIONS}

The practice of physical rehabilitation is increasingly focusing on the context of the individual rehabilitees as a way to encourage adherence. To support the rehabilitees perform exercises at home, the physiotherapists are prescribing individual rehabilitation therapy procedures and goals that are conducive for the rehabilitees to integrate them with their everyday routines at home $[23,24]$. These therapy procedures are arrived at in close collaboration with the individual rehabilitee [21] to understand the specific situation of the rehabilitee while exercising at home.

For example, a white paper on successful rehabilitation [23] emphasizes how it is imperative to integrate the rehabilitation treatment with the physical routines and the social relations of the rehabilitees in order to be successful. Nicholls and Gibson [24] call for a move towards a holistic approach for rehabilitation practice. They stress how successful physiotherapy requires the therapists to develop a more holistic view than the current focus on the injured biophysical body and include the everyday physical and social situation of the rehabilitees.
Another example [21] describes how having specific, achievable goals that are close to an individual's everyday environment will increase the motivation of the individual to engage in the therapy. They identify four components of a goal-oriented physical therapy process, one of which is the setting of goals that are meaningful for the individuals-goals that are tuned to the activities of daily living (ADL) such as walking to the store, picking up a towel, wearing socks, etc. The rehabilitees and the therapists have to periodically monitor the achievement of these goals in order to train and support the rehabilitees to achieve them.

In addition to this leaning towards a broader understanding of physical rehabilitation-in-context, the domain is moving towards a localized approach, where the professional physiotherapists fine-tune their prescriptions based on the individual rehabilitee's situation at hand. Research in the past $[7,22,26]$ recommends that the physical therapists closely engage with the specific, everyday needs of their rehabilitees, fine-tuning their prescriptions collaboratively.

Hence, we argue that it is fruitful for the designers of pervasive technology for supporting the self-monitoring of physical rehabilitation to take advantage of these moves of the practice towards integrating therapy to the specific situations of the individual rehabilitees.

\section{CONTEXT FOR ADHERENCE}

We look towards phenomenological accounts within the field of Human Computer Interaction (HCI) as a theoretical source for understanding the context where rehabilitees adhere to their therapy. These accounts [11,29] offer an alternative view of context to highlight how context is not a pre-given stable set of parameters, but a constantly 'emerging relation' between human actions and their settings. In particular, [11] highlights how when an individual acts by engaging with other individuals and things in a particular setting, he/she produces a context within which his/her actions become meaningful. Hence, the context is always for a purpose, for performing a set of particular actions by engaging with the social and physical particularities of a setting.

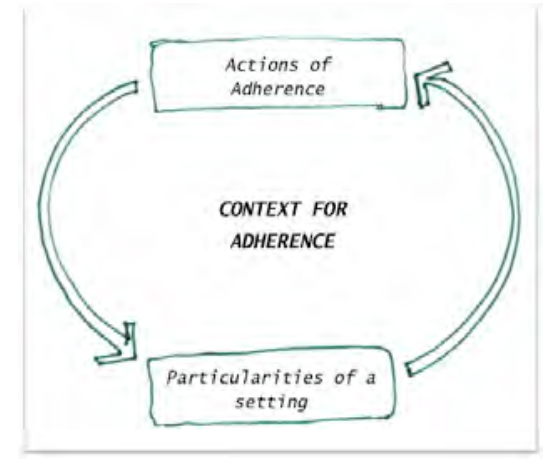

Figure 1. the emergent context for adherence

When viewed from the phenomenological understanding of context, it becomes apparent how the particularities of a setting - people and objects - that a rehabilitee engages with, become a very distinct context where performing the exercises makes sense for the rehabilitee. A particular context for 
adherence comes into being through the enactment of the interrelation between actions of adherence and the setting (see Figure 1).

\section{We define context for adherence as:}

An emerging relation between the particular actions that the rehabilitees perform in order to adhere with their treatment and the particular setting within which these actions are performed.

Adhering to a rehabilitation treatment involves different actions that are performed over time and across different settings, be it the clinic or home. The phenomenological perspective highlights how the clinic or the home are not mere containers for these actions, they constantly shape the rehabilitation process by offering a range of social and material particularities that the rehabilitees can engage with and respond to.

The home and the clinic are the settings that offer different objects, people, and social relations and norms. The rehabilitees engage with the particularities of each setting, taking advantage that they offer to adopt and appropriate the prescribed treatment so that adhering with the treatment makes sense. Even as the particularities shape how a rehabilitee performs and makes sense of his/her rehabilitation treatment, the particularities are in turn, shaped by the rehabilitees' actions. To take advantage of the particularities of a setting, the rehabilitees have to engage with them, reconfiguring, and repurposing them as resources for action. It is through this interplay between the actions of engagement with particularities and the setting that a particular context for adherence emerges.

To explain, we refer to an example from one of the design explorations described later on in the paper. Prabhakar, one of the rehabilitees who were a part of the design explorations, engages with his spouse Laxmi, as a resource to monitor how he performs his back-strengthening exercises. His physiotherapist at the hospital taught him these exercises after he suffered a stroke. At home he does this exercise always on the bed in the living room, twice a day. As his movements are restricted to his home, visiting the hospital to take guidance from the physiotherapist is extremely difficult for him. His wife has to book a taxi, take the help of taxi driver to lift Prabhakar onto the taxi, wait in a long queue at the hospital, and repeat the process to come back home. Hence the couple visits the hospital once in two months, and performs the exercises at home as much as they can.

This example shows how Prabhakar's performance of the exercises is shaped by the socio-material particularities at his home. These particularities are constituted by his physiotherapist's instructions about the exercises, or what he and his wife Laxmi remember of these instructions, the restriction of his movements, the bed in the living room, his wife Laxmi, the particular form of exercise, all shaping how Prabhakar performs his exercises. At the same time, as Prabhakar engages with these particularities, he actively modifies them. He engages with the bed as a resource to support his back, Laxmi as a resource to monitor how he performs the exercises and for encouragement. This engagement means that the bed has to be cleaned and made up regularly by Laxmi as it also acts as a couch in the living room for any visitors. Furthermore, Laxmi has to dedicate her time to monitor and guide Prabhakar twice a day.

The phenomenological perspective highlights how through these engagements with the setting, Prabhakar creates a context where him performing the exercises becomes meaningful.

\section{EMBODIED-SELF-MONITORING: EMBRACING THE EMERGENT CONTEXT}

Further, taking the phenomenological perspective [11] on self-monitoring foregrounds how the self-monitoring actions that the rehabilitees perform in order to adhere to the treatment-such as, measuring, recording, observing, reflecting, sharing, etc.-are embodied in the particular contexts for adherence. That is, the actions of self-monitoring are shaped by the particularities of a setting within which these actions are performed, and in turn these actions shape the setting. In this sense, we see the rehabilitee's engagement with the prescribed exercise instructions and tools as embodied actions through which he/she constantly takes advantage of the opportunities for adoption and appropriation of the prescribed treatment in context.

Looking back through this lens at the concept definition of self-monitoring [30], we see self-monitoring as being embodied in the world. In order to sensitize and orient the design towards how self-monitoring is embodied in the particular context for adherence, we propose the theoretical concept of embodied-self-monitoring as:

Measuring, recording, observing, and performing other such self-monitoring actions through engaging with the particularities of a setting for adhering to a prescribed treatment or therapy.

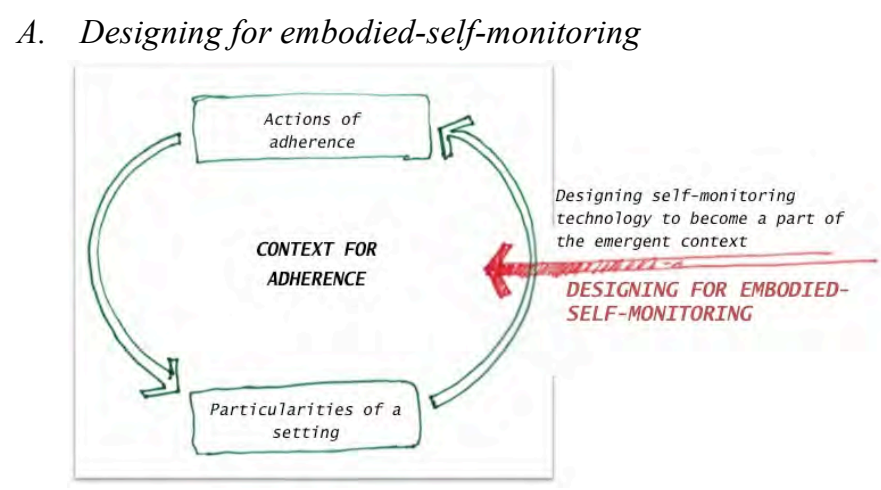

Figure 2. designing for embodied-self-monitoring

Moving towards design from this understanding about embodied-self-monitoring implies taking a stance to embrace the way a particular context for adherence emerges. In line with [11], we propose that designing for embodied-self-monitoring refers to foregrounding the embodied nature of self-monitoring in the design of pervasive self-monitoring technology (see figure 2). Hence, we understand designing for embodied-selfmonitoring as, 
Designing pervasive self-monitoring technology for offering opportunities for the rehabilitees to engage with the technology and through this engagement make the technology become a part of how they adhere with their therapy.

\section{EXAMPLES}

We took this understanding about context for adherence and self-monitoring of physical rehabilitation and explored how we can embrace them in the design for self-monitoring of physical rehabilitation in three different design situations. While these explorations are reported in detail [4,5], in this paper we synthesize our learning across the individual explorations. In each of the explorations we looked at how the individual rehabilitees engage with their physical and social particularities to adhere to their therapies. We formulated design visions based on these observations.

We used Arduino and Flash, in combination with Wizardof-Oz techniques, to make three interactive sketches [6] that are available for experience. The sketches were intended as early suggestions of possible solutions to help inspire further exploration and co-exploration with the rehabilitees, their spouses and therapists. We took these interactive sketches to the homes of the rehabilitees, asking them to engage in a series of in-situ enactments of how our sketches could be become part of their ongoing rehabilitation processes.

\section{A. ReSwing}

The situation was of Gita, and her husband, Kumar, live in Lonand, a village that is about $80 \mathrm{~km}$ from Pune, India. Gita is a 74-year-old lady who has had her knee joints replaced five years back, from a hospital in Pune, after which she underwent three months of physiotherapy to be mobile and reduce the pain. Her doctor prescribed her an exercise regime to continue at home so that she remains mobile and not experience any pain.

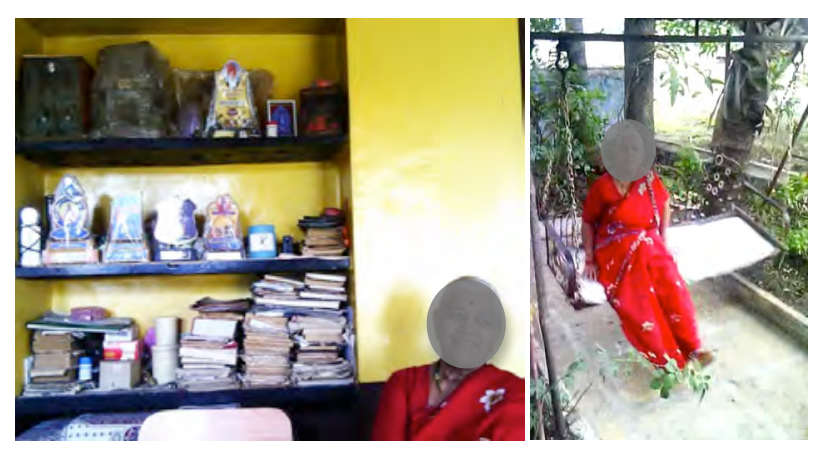

Figure 3. Gita in her living room with her trophies; and exercising on the swing in the garden

Looking at her situation from the phenomenological perspective, we could see how Gita has integrated her knee exercises with the pleasurable activity of the swing (see figure 3 ). She engages with the swing, and the pleasure of being on the swing, as resources to motivate her to perform her knee exercises. Another thing that we took inspiration from is the way she engaged with the trophies and awards in her living room turning them as resources to tell a story about her active life post rehabilitation (see figure 3). Additionally, Gita mentioned how over the five years, she has developed an innate sense of the relation between her not doing her exercise and the increasing pain. She knows that if she is travelling it is hard for her to exercise, and the pain in her knees gradually increases if she does not exercise for a week. However, this 'period of a week' is her measure through experience, and not an objective measurement of time. In other words, she engages with her past experience turning it as a resource to develop an awareness of the relation of exercise and pain, and further engages with this awareness as a resource to encourage her to keep exercising as and when she can.

We envisioned how Gita may engage with a digital technology as a resource for measuring, recording and making her swing activity a legitimate form of exercise. We also envisioned how Gita can engage with a digital technology as a resource to give a material form to her felt awareness, making it visible to her and other people visiting her home, so as to reinforce the encouraging role the awareness plays.

We formed an early version of these visions in the form of ReSwing sketch. This design sketch consists of two components: a mat with an accelerometer connected to an Arduino and Zigbee module (Figure 4), and a trophy with three LED lights connected to another Arduino and Zigbee module (Figure 4). The trophy is designed to fit the aesthetics of the other trophies that she has in her home, with the text congratulating her and her husband of being successful in her rehabilitation program.

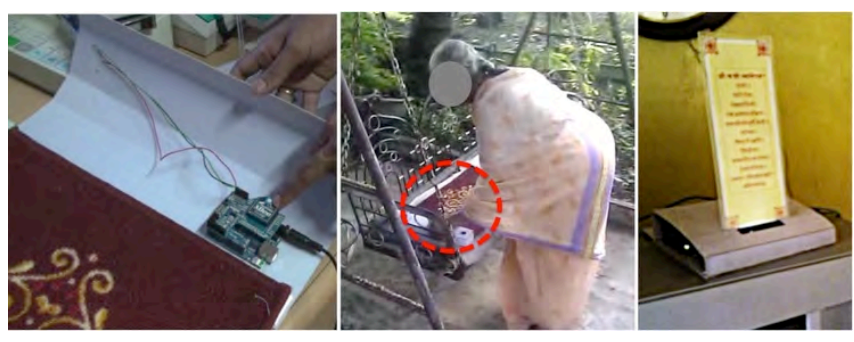

Figure 4. ReSwing Mat and Trophy sketch

When Gita keeps the mat on the swing and does her exercise sitting on it, the central LED of the three LEDs lights up, and the other two flickers. The mat communicates the accelerometer readings to the LEDs in the trophy via Zigbee. When the mat is rolled and kept after using, the central LED remains lit and the two side ones switch off. The central LED then fades off gradually over time ( 24 hours) till Gita uses the mat again. The trophy lights up and fades off based on how much the mat was used, showing Gita the frequency of her exercise.

Gita can display the trophy in her living room, along with her other trophies, and may engage with it as a 'prop' in her recollection and retelling of her rehabilitation story to new and would-be patients sent to her by her doctor. Gita can use the mat on the swing or keep it on the foot-operated sewing machine. It will record both her activities and trigger the LEDs on the trophy (see Figure 4). 


\section{B. ReBreath}

This was of a situation of Madhav, a 69-year-old man is an active member of the community and a secretary of the neighborhood senior citizens group, taking care of a physiotherapy center, an activity center, and a gym. Due to the nature of his activities he suffers from weak knees, and according to Ravi, his physiotherapist at the local physiotherapy center, he is couple of years away from a knee replacement. Ravi has prescribed him an exercise regime to push the surgery further. Madhav has to keep a soft pillow or a rolled towel under his knee while lying down, apply pressure on the towel and count till 10 . He has to repeat this 10 times each, while lying down and while sitting everyday. However as he admitted in the interview, he does not consistently perform these exercises. Furthermore, Madhav is supposed to visit the therapist once every week to discuss his progress, but he drops in sporadically as he is busy. And as the secretary of the senior citizen group that runs the therapy center, Ravi cannot help much to enforce the periodicity of his visits, but remind him of his weakening knees.

At the same time, as an ex-body builder, he is actively engaged in exercising at the nearby gym that he started. He goes to the gym everyday at $4 \mathrm{am}$, performs a series of upper body exercises, lifts weights, and is back home by $5 \mathrm{am}$. He and his wife, who is a yoga enthusiast, then do a series of yogic breathing exercises. Madhav is proud of his 'fit' body, recollecting only his gym exercises and the yogic breathing, whenever we asked about his exercise regime at home, and conveniently forgetting about the knee exercises.

From the phenomenological perspective, we saw how he engages with the weight-lifting exercises as resources to remain fit, and with the yogic breathing exercises as resources for being mentally agile for managing all the social activities he is involved with. He engages with his knee exercises only when he feels the pain in his knees.

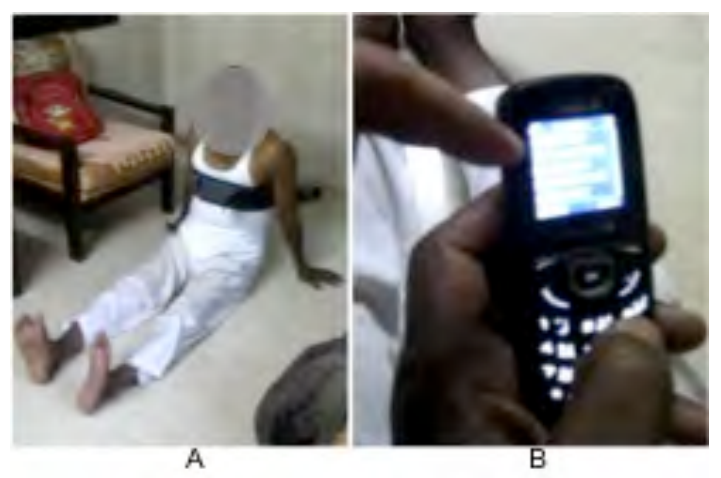

Figure 5. A: Trying out the ReBreath sketch, B: The text message after the exercise

We envisioned a digital self-monitoring technology that Madhav can engage with as a resource to merge his favorable activities of yogic breathing and weight lifting with the knee exercises. We also envisioned a digital self-monitoring technology that Madhav may engage with as a resource to record the daily number of knee exercises he performs and employ this record as a resource to negotiate with Ravi.
ReBreath is a support belt used while lifting weights in the gym that Madhav wears around his chest while doing his knee exercises (Figure 5). During the exercise, Madhav lies down with a rolled towel below his knees. When he applies pressure on the towel by pressing down the knees, he takes-in his breath, holding it as much as he can, and releasing it as he eases his knee back. The chest-belt detects the change in the chest form and counts every expansion and retraction as one count. After 10 such counts, an LED is lit indicating that his exercise is done for the day. Further, the belt will send this information as a text message to his phone. We sketched this feature by employing a Wizard-of-Oz technique, manually sending the text message during demo and try-out with Madhav.

\section{ReExercise}

This was the situation of Prabhakar a 78-year-old man who had a stroke two years earlier that has left him partially paralyzed. He can walk around the house with the help of a walking stick, but cannot go out due to a weak nervous system. He lives with his 74-year-old wife Laxmi in a modest house with a living room, kitchen, and a single bedroom. The couple described how, after the stroke, which occurred two years ago, Prabhakar is now dealing with a weak spine, and has to perform exercises everyday at home. He performs his physiotherapy exercises twice a day: after breakfast and before dinner. These exercises consist of lying down on the hard bed in the living room (Figure 6) and lifting his torso by pushing his weight onto his elbows. When Prabhakar demonstrated these exercises, Laxmi told him to keep his elbows straight and also intervened to make them straight (Figure 6).

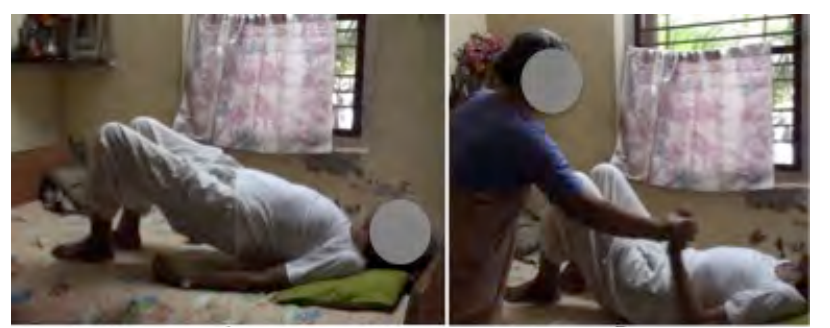

Figure 6. Prabhakar exercising at home; Laxmi motivating and guiding him

Through the phenomenological lens we saw how Prabhakar engaged with Laxmi as a resource to motivate and guide him to perform the exercises. Further, we saw the way the couple engages with religious idols and spiritual activities as resources to deal with their displeasure about being old and lonely.
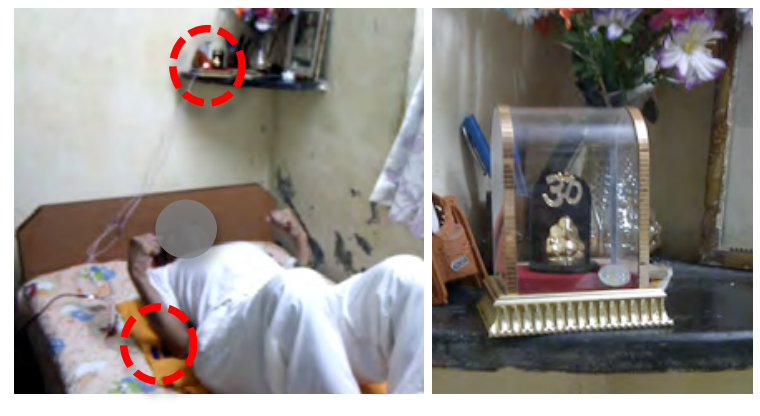

Figure 7. Prabhakar exercising with the ReExercise mat connected to the LED on Ganesha idol 
Moving towards design, we envisioned how Prabhakar may engage with a digital self-monitoring technology as a resource for closely involving Laxmi in his exercises, and as a resource for Laxmi to continue and enhance her involvement in her husband's exercises. We also envisioned how Prabhakar may engage with a digital technology as a resource for turning his performance of the exercises as a way of praying to god.

The ReExercise sketch constitutes an exercise mat with a FSR connected to a Lilypad Arduino. An LED is connected to the Arduino and is fixed on a small idol of Ganesha (Figure 7), the elephant god worshipped by the couple. During his exercise, Prabhakar lies on the exercise mat and positions his elbow on the FSR. The force he puts on the elbow when lifting his torso is registered, and the LED in front of Ganesha is lit. The brightness of the LED is based on the force he exerts on the FSR, the maximum being the force applied when his hand is perpendicular to ground, as prescribed by his doctor. The LED switches off gradually after 8 hours, and he has to switch it on again the next day by exercising.

\section{THREE OPPORTUNITIES}

The explorations brought forward different scenarios of how supporting embodied-self-monitoring opens opportunities for the rehabilitees to engage with the digital technology as a resource to shape their ways of adherence. We synthesize these scenarios to highlight how supporting embodied-selfmonitoring offers three of the possible opportunities, detailed as follows:

\section{1) Opportunity to integrate the exercises with the objects} at home.

Presenting the self-monitored data in the form of physical artifacts pointed to how supporting embodied-self-monitoring could offer opportunities for the rehabilitees to engage with the recorded data as a resource to integrate the exercises with the things and objects they surround themselves with at home.

During the ReSwing exploration, Gita employed the trophies and the decorative objects that she makes as objects to tell her life stories. This prompted us to speculate if she can similarly engage with the recorded self-monitored data to tell stories about her rehabilitation process to prospective rehabilitees visiting her for advice. ReSwing by displaying the self-monitored data in the form of a trophy opens an opportunity for Gita to engage with it and make it a fixed object in her living room, along with other trophies and awards. Gita may employ the rehabilitation trophy as a prop to share rehabilitation stories, similar to the way she shares her music stories, with her friends and family. Gita mentioned how, during the deployment week, she discussed the trophy to her visiting daughter showing how she exercises with the swing and how that is reflected in the trophy. Kumar, when he saw his name along with the name of his wife on the trophy, recollected his efforts in the rehabilitation of his wife and shared the episodes with us.

ReExercise explores this possibility for integration with objects by fixing the LED based feedback in front of an idol of Ganesha. The LED changes its brightness based on the amount of pressure Prabhakar exerts on his elbow during his exercise.
Having this feedback, which will be persistently lit for 8 hours after he exercises, as part of the idol presented Prabhakar and Laxmi an opportunity to convert the self-monitored data as a spiritual object part of their living room.

2) Opportunity to integrate the exercises with other everyday activities.

We found how by supporting the rehabilitees to integrate the self-monitored data with the different objects at home, further offered opportunities for them to integrate the exercises as part of other everyday activities that the rehabilitees perform.

Gita already had integrated her knee exercises with enjoying the ride on the swing in her garden. We took advantage of Gita's integrated way of exercising, and intended to open an opportunity for her to engage with the digital technology as a resource to keep a track of when she exercises, and make this data visible as part of her living room. The dexterous form of the ReSwing-mat offered opportunities for Gita to use it on the swing, or as she mentioned and demonstrated during the exploration, on the foot-operated sewing machine as resource through which she can track how she moves her knees during these activities.

ReBreath, meanwhile, came about in a situation where Madhav preferred to perform his weight lifting and yogic breathing exercises rather than the prescribed knee exercises. The sketch of ReBreath, by intending to measure the number of times Madhav holds his breath, pointed to how he could engage with the yogic breathing exercises as a resource to count and keep track of his knee exercises. The form of ReBreath as a weight-lifting support belt further pointed to how Madhav's engagement with digital technology opens up an opportunity for him to, firstly, keep count of his weight-lifting exercises along with the count of his knee exercises and secondly, as he demonstrated to perform his simple knee exercises while he is doing some of the stretching and warming-up exercises at the gym. In this sense, exploring how to support Madhav's embodied actions of self-monitoring opened opportunities for him to envision how he could engage with digital technology as a resource to integrate the 'boring and mundane' knee exercises with the more 'exciting and favorable' gym and breathing exercises.

ReExercise further explored this thread of supporting embodied-self-monitoring to offer opportunities for the rehabilitees to integrate the tedious prescribed exercises with other more exciting or engaging activities. Prabhakar and Laxmi's spiritual ways of living, which was manifested in the range of idols of gods adorning their living room and the prayer routines, were the more exciting or engaging activities that ReExercise focused on. By lighting the LED display in front of Ganesha, Prabhakar can engage with the digital technology as a resource to convert his exercises as a way of praying: Lighting a lamp in front of the idol twice a day.

3) Opportunity to integrate the exercises with close-social relations.

Finally, we found how supporting embodied-selfmonitoring offered opportunities for the rehabilitees to engage with digital technology as a resource to integrate and bring 
their close social relations as part of the exercises. We encountered this possibility accidentally during the ReSwing exploration, which was explored further in ReExercise.

Kumar was actively engaged in managing the physical rehabilitation process of his wife, Gita. This motivating role became apparent when we visited their house to see how they were living with the sketch of ReSwing. We did not design the frequency of the flickering LEDs to reflect the speed with which Gita swung back and forth on the swing. However, we noticed that when Gita exercised with the swing in her garden, Kumar was in the living room, 'reading' the frequency of the flickering LEDs on the trophy and telling her if she has to increase her speed or slow down. This happen-by-chance experience pointed out how Gita engaged with the ReSwing swing as a resource to involve Kumar in closely monitoring her exercises.

We further explored this insight during ReExercise. Prabhakar being a Hindu cannot show his feet towards the idol of Ganesh. Hence, whenever he exercises with the ReExercise sketch, the idol is always on the alcove behind his head, an arrangement that was formalized during the demonstration. This arrangement offered an opportunity for Prabhakar to continue Laxmi's involvement to read the feedback from the LEDs and communicate it to him. At the same time, this arrangement opened opportunity for Laxmi to engage with the digital technology as a resource to gently encourage Prabhakar and remind him of the correct way to hold his hand while exercising.

\section{DISCUSSION}

\section{A. Embodied-self-monitoring: a way to make self-monitoring technology become part of the familiar settings.}

Increasingly pervasive and mobile technology is explored as a tool for supporting the rehabilitees to adhere with the treatment at home. The works predominantly explore the quality of playfulness and the immersive environment of the gaming world as a possible motivation for people to engage with their physiotherapy exercises $[1,13,14,15]$. At the same time, there are works that aim to address adherence with medicinal treatment $[8,17,18,25]$ and general fitness regimes $[9,10,19]$. These works, implicitly or explicitly, rely on the clinically well-established concept of self-monitoring $[16,30]$ to guide the design and development; they focus on the design of digital technological tools that, either automatically or manually, measure and record how the patients adhere with their treatment, process the data collected and present the data to the patients to make them aware of their adherence. In other words, the focus is on the design of pervasive self-monitoring technology.

Meanwhile, there is a growing concern to take into consideration the complexities of adhering with prescribed treatment at home, which is a 'lived' everyday setting. Recent works $[2,3,20]$ urge the researchers in the domain to consider the home as a distinct, and yet a rich setting for rehabilitation and treatment activities, rather than an extension of the clinic. The rationale here is to look for ways in which clinical rehabilitation therapies can be made familiar with the way people live at home. Furthermore, as mentioned above, the field of physiotherapy is moving towards a localized approach where they encourage the rehabilitees to integrate exercises with the everyday activities that they are already familiar with and engage in.

We position Embodied-self-monitoring as a theoretical ground to design novel self-monitoring technology that can, in ways similar to the physiotherapy practice, be engaged with as part of familiar, ongoing objects, activities and social networks. As the examples demonstrated, embodied-self-monitoring gave us the ground to frame the rehabilitees' already ongoing ways of adherence and make them tenable for design. For instance, Gita has created a context through her engagement with the swing over five years for adhering with her therapy and becoming aware of the relation between not exercising and pain. By framing this context through the phenomenological perspective, we could imagine ways in which Gita can engage with a self-monitoring technology as part of this ongoing activity of exercising. Other designers can frame other aspects of Gita's ongoing engagement and design novel selfmonitoring technology that can become part of Gita's context in different ways.

Hence embodied-self-monitoring acts as a 'lens' that generates a range of possibilities for the designers to design pervasive self-monitoring technology that the rehabilitees can engage with and integrate with their familiar, emerging contexts for adherence.

\section{B. Limitations and future work}

However, this work is only a starting point towards addressing the issues of supporting adherence to physical rehabilitation. The design explorations presented here are early forms of rudimentary bespoke technology that hint towards a possible solution for the individual rehabilitees. Currently we are considering how to move from the focus on individuals towards addressing a broader group of rehabilitees.

\section{CONCLUSION}

Through this paper, we presented embodied-selfmonitoring as a fruitful theoretical concept that offers an a priori orientation for the designers to fruitfully embrace the emergent context for adherence in the design of pervasive selfmonitoring technology for supporting rehabilitee adherence. In particular the theoretical concept made us foreground the embodied and situated nature of how the rehabilitees adhere to their therapy through engaging with the particularities of their home settings. Foregrounding this embodied nature involved a focus to facilitate rehabilitee engagement with the designed technology as one of the resources that works in concert with the already engaged particularities of the setting in order to shape the rehabilitee's ways of adherence. We demonstrated how by designing for embodied-self-monitoring gave three kinds of opportunities for the rehabilitees to engage with pervasive self-monitoring technology as a resource to integrate exercises with familiar objects, everyday activities and intimate social relations.

These three findings are in no way a complete picture, but we consider them as a beginning of an articulation of a larger 
space of possibilities. By presenting the concept and the findings we invite the community to engage in a process of exploring and articulating the larger space of possibilities. Through this paper, we open the space for the community to not only consider how the context at home influences adherence, but also draw from the physiotherapy practice to embrace this relation between context and adherence, to design pervasive self-monitoring technology that can become an integral part of this emergent context.

\section{ACKNOWLEDGMENT}

We thank all the participant rehabilitees and the physiotherapists. We thank the reviewers for their valuable comments and critique.

[1] Alankus, G., Lazar, A., May, M., \& Kelleher, C. (2010). Towards customizable games for stroke rehabilitation. Proceedings of the 28th international conference on Human factors in computing systems, CHI '10 (pp. 2113-2122). New York, NY, USA: ACM.

[2] Axelrod, L., Fitzpatrick, G., Burridge, J., Mawson, S., Smith, P., Rodden, T., \& Ricketts, I. (2009). The reality of homes fit for heroes: design challenges for rehabilitation technology at home. Journal of Assistive Technologies, 3(2), 35-43.

[3] Axelrod, L., Fitzpatrick, G., Balaam, M., Mawson, S., Burridge, J., Ricketts, I., Smith, P. P., et al. (2011). A toolkit to explore lived experience of motivation: When words are not enough. 2011 5th International Conference on Pervasive Computing Technologies for Healthcare (PervasiveHealth) (pp. 32-39). Presented at the 2011 5th International Conference on Pervasive Computing Technologies for Healthcare (PervasiveHealth), IEEE.

[4] Bagalkot, N., Sokoler, T., (2012), Unboxing the Tools for Physical Rehabilitation: Embracing the Difference between the Clinic and Home. Accepted for publication in $7^{\text {th }}$ Nordic Conference on Human-Computer Interaction (NordiCHI'12). ACM.

[5] Bagalkot, N. L., Sokoler, T., \& Shaikh, R. (2012). Integrating physiotherapy with everyday life: exploring the space of possibilities through ReHandles. Proceedings of the Sixth International Conference on Tangible, Embedded and Embodied Interaction, TEI '12 (pp. 91-98). New York, NY, USA: ACM.

[6] Buxton, B. (2007) Sketching User Experiences: Getting the Design Right and the Right Design. Morgan Kaufmann Publishers Inc.

[7] Campbell R, Evans M, Tucker B, Quilty B, Donovan JL. (2001). Why don't patients do their exercises? Understanding non-adherence with physiotherapy in patients with osteoarthritis of the knee. $J$ Epidemiol Commun Health, 55:132-8.

[8] Chen, F., Hekler, E., Hu, J., Li, S., \& Zhao, C. (2011). Designing for context-aware health self-monitoring, feedback, and engagement. Proceedings of the ACM 2011 conference on Computer supported cooperative work, CSCW '11 (pp. 613-616). New York, NY, USA: ACM.

[9] Consolvo, S., Everitt, K., Smith, I., \& Landay, J. A. (2006). Design requirements for technologies that encourage physical activity. Proceedings of the SIGCHI conference on Human Factors in computing systems - CHI 'O6 (p. 457). Presented at the the SIGCHI conference, Montr\&\#233;al, Qu\&\#233;bec, Canada.

[10] Consolvo, S., McDonald, D. W., \& Landay, J. A. (2009). Theory-driven design strategies for technologies that support behavior change in everyday life. Proceedings of the 27th international conference on Human factors in computing systems, CHI '09 (pp. 405-414). New York, NY, USA: ACM.

[11] Dourish, P. (2001) Where the Action Is: the Foundations of Embodied Interaction. MIT Press

[12] Fergus, P., Kifayat, K., Cooper, S., Merabti, M., \& El Rhalibi, A. (2009). A framework for physical health improvement using Wireless
Sensor Networks and gaming. 3rd International Conference on Pervasive Computing Technologies for Healthcare, 2009. PervasiveHealth 2009 (pp. 1-4). IEEE.

[13] Geurts, L., Vanden Abeele, V., Husson, J., Windey, F., Van Overveldt, M., Annema, J.-H., \& Desmet, S. (2011). Digital games for physical therapy. Proceedings of the fifth international conference on Tangible, embedded, and embodied interaction - TEI ' 11 (p. 117). Presented at the the fifth international conference, Funchal, Portugal.

[14] Grönvall, E., \& Kramp, G. (2011). LinkLights: a modular, user adaptable system to support rehabilitation practices. Proceedings of the 4th International Conference on PErvasive Technologies Related to Assistive Environments, PETRA '11 (pp. 3:1-3:8). New York, NY, USA: ACM.

[15] Holden, M. K. (2005). Virtual Environments for Motor Rehabilitation: Review. CyberPsychology \& Behavior, 8(3), 187-211. doi:10.1089/cpb.2005.8.187

[16] Korotitsch, W. J., \& Nelson-Gray, R. O. (1999). An overview of selfmonitoring research in assessment and treatment. Psychological Assessment, 11(4), 415-425.

[17] Lee, M. L., \& Dey, A. K. (2010). Embedded assessment of aging adults: A concept validation with stakeholders. Pervasive Computing Technologies for Healthcare (PervasiveHealth), 2010 4th International Conference on-(pp. 1-8). IEEE.

[18] Lee, M. L., \& Dey, A. K. (2011). Reflecting on pills and phone use. Proceedings of the 2011 annual conference on Human factors in computing systems - CHI '11 (p. 2095). Presented at the 2011 annual conference, Vancouver, BC, Canada.

[19] Maitland, J., Sherwood, S., Barkhuus, L., Anderson, I., Hall, M., Brown, B., Chalmers, M., et al. (2006). Increasing the Awareness of Daily Activity Levels with Pervasive Computing. Pervasive Health Conference and Workshops, 2006 (pp. 1-9). IEEE.

[20] Maitland, J., \& Chalmers, M. (2010). Self-monitoring, self-awareness, and self-determination in cardiac rehabilitation. Proceedings of the 28th international conference on Human factors in computing systems, CHI '10 (pp. 1213-1222). New York, NY, USA: ACM.

[21] Mastos, M., Miller, K., Eliasson, A. C., \& Imms, C. (2007). GoalDirected Training: Linking Theories of Treatment to Clinical Practice for Improved Functional Activities in Daily Life. Clinical Rehabilitation, 21(1), 47-55.

[22] McClain, C. (2005) Collaborative Rehabilitation Goal Setting, Topics in Stroke Rehabilitation, Volume 12, Issue 4.

[23] National whitepaper on rehabilitation, (2004) http://www.marselisborgcentret.dk/fileadmin/filer/hvidbog/hvidbog.pdf.

[24] Nicholls, D.A. \& Gibson, B.E., (2010). The body and physiotherapy. Physiotherapy Theory and Practice, 26(8), pp.497-509.

[25] Pavel, D., Callaghan, V., \& Dey, A. K. (2010). Looking Back in Wonder: How Self-Monitoring Technologies Can Help Us Better Understand Ourselves. 2010 Sixth International Conference on Intelligent Environments (IE) (pp. 289-294). Presented at the 2010 Sixth International Conference on Intelligent Environments (IE), IEEE.

[26] Sluijs, E. M., Kok, G. J., \& Zee, J. van der. (1993). Correlates of Exercise Adherence in Physical Therapy. Physical Therapy, 73(11), 771-782.

[27] Sokoler, T., Löwgren, J., Eriksen, M. A., Linde, P., \& Olofsson, S. (2007). Explicit interaction for surgical rehabilitation. Proceedings of the lst international conference on Tangible and embedded interaction, TEI '07 (pp. 117-124). New York, NY, USA: ACM.

[28] Stolterman, E. \& Wiberg, M., (2010), Concept-Driven Interaction Design Research. Human - Computer Interaction, 25(2), p.95-118.

[29] Svanaes, D., (2001) Context-Aware Technology: A Phenomenological Perspective. Human - Computer Interaction, 16, pp. 379-400. Lawrence Erlbaum Associates, Inc.

[30] Wilde, M. H., \& Garvin, S. (2007). A concept analysis of self-monitoring. Journal of Advanced Nursing, 57(3), 339-350. 